\title{
Effect of restricting silage feeding prepartum on time of calving, dystocia and stillbirth in Holstein- Friesian cows
}

\author{
David E. Gleeson, Bernadette O'Brien and John F. Mee \\ Teagasc, Moorepark Dairy Production Research Centre, Fermoy, Co. Cork, Ireland
}

\section{Corresponding author:}

Dr. John F. Mee, Teagasc, Moorepark Dairy Production Research Centre, Fermoy, Co. Cork, Ireland

Email: john.mee@teagasc.ie

Tel: +353254 2387

Fax: +3532542340

\begin{abstract}
A study was carried out to investigate the effect of restricting silage feeding on time of calving and calving performance in Holstein-Friesian cows. In the treatment group ( $\mathrm{n}=1,248$ cows, 12 herds) silage feeding commenced in the evening (17:00 to 20:00h), after a period of restricted access ( 2 to $10 \mathrm{~h}$ ) while in the control group ad-libitum access to silage was provided over the $24 \mathrm{~h}$ period ( $\mathrm{n}=1,193$ cows, 12 herds). Daytime and nighttime calvings were defined as calvings occurring between the hours of 06:30 and 00:29 and between 00:30 and 06:29, respectively. Restricting access to silage resulted in less calvings at night compared to cows with ad-libitum access to silage (18 vs $22 \%, P<0.05)$. Cows with restricted access to silage had a higher percentage of difficult calvings $(11 \mathrm{vs} 7 \%, P<0.001)$ and stillbirths ( 7 vs $5 \%, P<0.05$ ) compared to cows in the control group. The percentage of calvings at night was lower $(13 \%)$ when access to silage was restricted for $10 \mathrm{~h}$ compared to 2,4 or $6 \mathrm{~h}(22,18,25 \%$, respectively) $(\mathrm{P}<0.001)$. Calf sire breed, calf gender or cow parity did not influence time of calving. In conclusion, offering silage to pregnant Holstein-Friesian cows in the evening, after a period of restricted access, reduced the incidence of nighttime calvings, but increased the incidence of dystocia and stillbirth.
\end{abstract}

Key words: dairy cows, calving, silage feeding, dystocia, stillbirth

Irish Veterinary Journal Volume 60 Number $11,667-6712007$

\section{Introduction}

In the Irish spring-calving milk production system, farmers attempt to have the majority of cows calving during a 12week period. Most labour is available on farms from 06:00 to $17: 00 \mathrm{~h}$ and during this time maximum supervision may be given to calving. However, calvings outside of this time can put a strain on labour resources and can also result in less supervision at calving. This can, in turn, lead to an increased risk of unattended dystocia and associated disorders such as retained placenta, metritis, poor fertility and untreated milk fever (Stevenson and Call, 1988). Increased supervision of calving should be possible if management practices could be adopted which would minimise the incidence of nighttime calvings.

The practice of feeding cows in late evening is considered by many farmers to prevent nighttime calving. An Irish farm labour survey found that $32 \%$ of farmers with herds of more than 30 cows restricted access to silage during the daytime and fed silage in the evening time in order to reduce the number of nighttime calvings (O’Brien et al., 2001). However, results from studies on the effect of feeding time on calving time are inconsistent. Clarke et al., (1983) reported that feeding Holstein cows a complete ration ad-libitum, two weeks prior to calving at 17:30h compared to $08: 00 \mathrm{~h}$, increased daytime calvings ( $72 \%$ vs $55 \%)$. In a further study, $80 \%$ of beef cows fed fresh material ad-libitum in late evening between 21:00 and 22:00h calved during the day (Yarney et al., 1979). However, Macmillan et al., (1985) showed that offering fresh grass ad-libitum to dairy cows at 07:00 to 16:00 or 19:00 did not increase the frequency of daytime calvings. Lowman et al., (1981) also suggested that the distribution of calving can be altered by changing both feeding time and introducing a restricted period of access to silage. Of cows offered silage at 22:00h, after a restriction period of $6 \mathrm{~h}, 79 \%$ calved between $06: 00 \mathrm{~h}$ and $22: 00 \mathrm{~h}$, whereas of cows offered silage ad-libitum at $08: 30 \mathrm{~h}, 57 \%$ calved during this daytime period.

These results suggest that feeding at 22:00h may be the optimum time, after a period of restricted silage access, to achieve the most calves born during daylight hours. The period of time that cows are without feed prior to the main feeding time may also be an influencing factor in minimising the number of calvings at night. The absence of control cows in some studies and the opportunity for at least some grazing may explain the lack of consistency in previous studies. The physiological mechanisms by which night 
feeding might reduce the incidence of nighttime calving are unknown. Changes in postural behaviour, intra-ruminal pressure and alteration in uterine prostaglandin profiles have been proposed. For example, rumen motility studies have indicated that the frequency of rumen contractions decreases during the hours immediately before calving. Thus, increased rumen contractions associated with feeding may influence calving time. In addition, Taverne et al., (2002) showed that the frequency of pre-calving myometrial contractures is not uniformly distributed over the 24 hours of the day but is significantly lower when cows are standing and feeding.

Given these conflicting results and anecdotal farmer evidence, Gleeson et al., (2003) carried out a pilot study in research dairy herds on the effect of altering feeding time on calving time. The encouraging results from that experiment prompted this large scale study in commercial dairy herds. The hypotheses tested in this study were firstly, that restricting access to silage during the daytime and allowing access in the evening time would reduce the number of nighttime calvings, and secondly that the reduction in the number of nighttime calvings would result in better calving supervision and therefore less dystocia and calf mortality. Thus, the objective of this study was to establish the effect of altering silage feeding time prepartum on time of calving and on calving performance.

\section{Materials and methods}

Twenty-four commercial dairy herds were enrolled in this study using the following selection criteria: springcalving dairy herd, located in Munster, herd size $\geq 30$ Holstein-Friesian cows and participant in either a farm labour study (O'Brien et al., 2001) or in a computerised recording system (Dairy MIS). Prior to selecting herds, a power calculation was carried out to determine the number of animals required in each group to detect statistically significant differences between groups. A total of 1,100 cows was required in each group to have an $80 \%$ probability of detecting a true difference of five percentage units at the $5 \%$ significance level where the night calving rate in the restricted group was $20 \%$. Clusters of cows (i.e., herds) were allocated to intervention and control treatments on the basis of the farmers' pre-calving feeding practices and herd size. All farms were visited prior to the start of the study and at regular intervals during the calving season to monitor feeding practices and to collect calving records. Twelve of the commercial herds had previous experience of feeding grass-silage in the evening to dry cows. The time period

Table 1: Effect of restricting access to silage prepartum on the percentage of calvings by night (00:30 to 06:29h), percentage of unassisted, slight assistance and difficult calvings and percentage of stillborn calves

\begin{tabular}{|l|c|c|c|}
\hline Calvings (\%) & $\begin{array}{c}\text { Restricted access } \\
(\mathrm{n}=1,248)\end{array}$ & $\begin{array}{c}\text { Ad-lib access } \\
(\mathrm{n}=1,193)\end{array}$ & P-value \\
\hline Nighttime & 17.71 & 21.71 & 0.05 \\
\hline Unassisted & 61.56 & 58.97 & $\mathrm{NS}^{1}$ \\
\hline Slight assistance & 26.98 & 34.34 & 0.001 \\
\hline Dystocia & 11.46 & 6.69 & 0.001 \\
\hline $\begin{array}{l}\text { Stillbirth } \\
\text { 1 NS=not significant }\end{array}$ & 6.91 & 4.82 & 0.05 \\
\hline
\end{tabular}

that cows were restricted from silage varied between farms and was categorised as 2 ( 1 herd), 4 (5 herds), 6 ( 2 herds) or 10 hours (4 herds). These herds continued this practice for the duration of the study and are referred to as the restricted group ( $n=1,248$ cows, 12 herds). Cows with restricted silage access were restricted either as a group ( $\leq 10$ cows/group) or as a complete herd. Cows restricted as a group were restricted within two weeks of calving while cows restricted as a herd were restricted approximately two weeks before the commencement of the calving season and throughout the calving season. The commencement of evening feeding, after restriction, varied between 17:00 and 20:00h (mean 19:15h) between farms. The remaining 12 herds (selected by pairing on herd size) had ad-libitum access to silage over the $24 \mathrm{~h}$ period and are referred to as the control group ( $n=1,193$ cows, 12 herds). The daily feeding time of fresh silage varied within a farm and between control farms but was generally between 09:00 and 16:00h. Cows were offered silage when the previous day's feed was consumed in order to avoid spoilage. The level of silage refusal was not recorded on these commercial dairy farms. Herd size ranged from 30 to 280 cows (median=92). The mean milk yield from the previous year was 5,219 litres/cow. Drinking water was available to all cows at all times. Cows were housed in cubicles and were moved to a straw-bedded maternity area at the point of calving. Daytime and nighttime calvings were defined as calvings occurring between the hours of 06:30 and 00:29 and between 00:30 and 06:29, respectively. The nighttime period was chosen as the time period when the least amount of labour would be available. All farms used closed circuit cameras installed in the calving area in addition to regular visits to the calving area, to observe calving. The time of calving, calf gender, breed of calf sire (Aberdeen Angus, Holstein-Friesian, Jersey, Montbeliarde) and dam lactation number were recorded. Assistance at calving was recorded using a scoring system: $1=$ no assistance; 2 =slight difficulty; 3 =serious difficulty; $4=$ very serious difficulty; and $5=$ caesarean section. Dystocia was defined as a calving with a score $\geq 3$. A stillbirth was defined as a calf born dead at full term. Abortions, induced calvings and multiple births were excluded from the data set. Data were recorded on pro forma duplicate sheets, collected monthly by a data technician and analysed using the chi-square procedure in Genstat 5 (Release 3.2). The effect of feed restriction was confounded with farm. Hence, to control for between farm differences herd sampling was restricted based on the selection criteria, experimental groups were blocked by herd size and the effects of potentially confounding farm variables (cow parity, calf sire breed and calf gender) on the dependent variables were included in the statistical analyses. Values of $\mathrm{P}<0.05$ were considered statistically significant.

\section{Results}

Restricting silage feeding time resulted in four percentage units less calvings at night compared to the control group $(\mathrm{P}<0.05)$ (Table 1). However, there was a large variation between herds in the proportion of cows calving by night, 


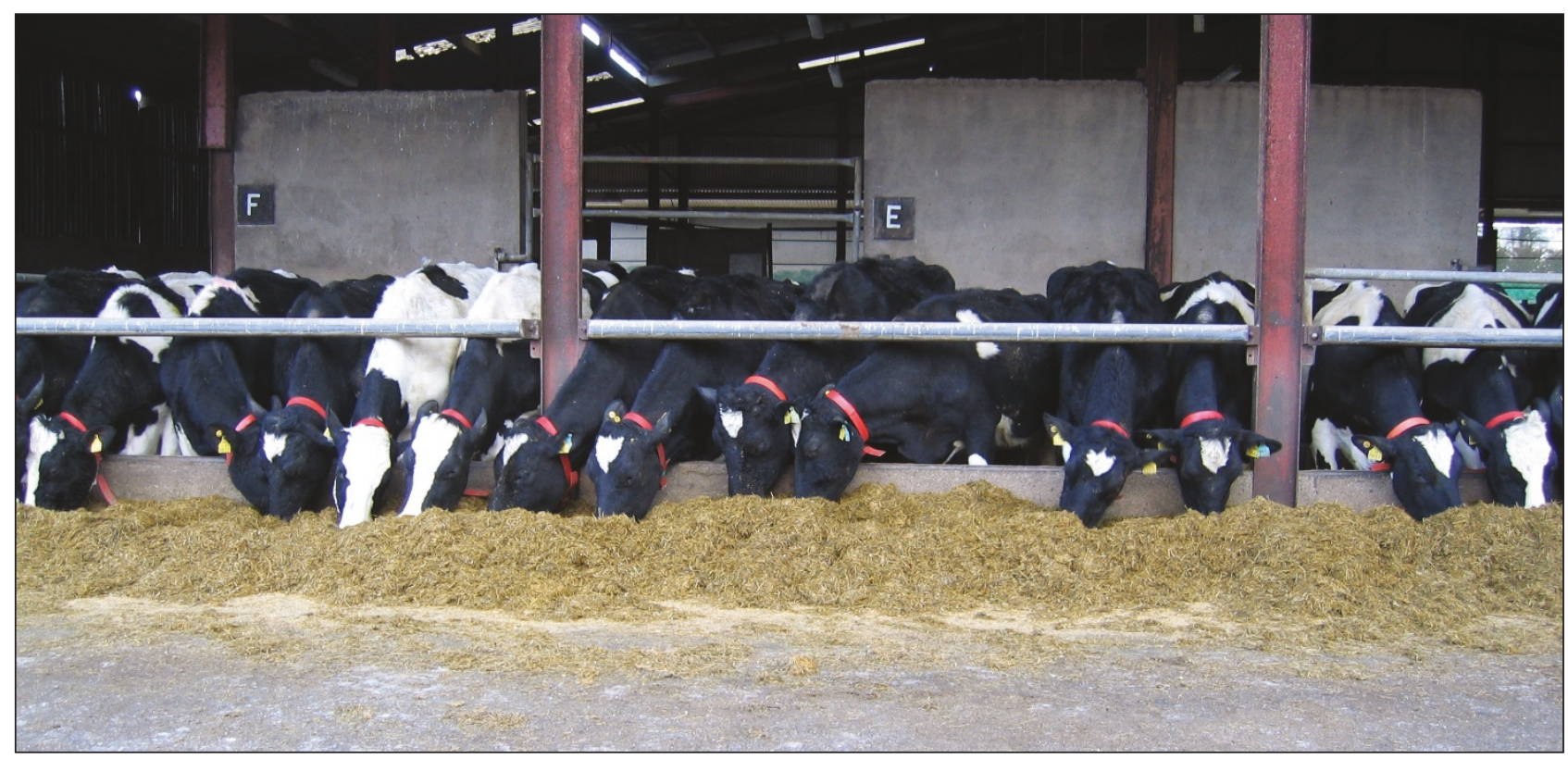

This study looked at the effect of restricting silage feeding on time of calving and calving performance in Holstein-Friesian cows.

regardless of feeding system. This reduction in nighttime calvings varied between two and 16 percentage units, by herd. The percentage of unassisted calvings did not differ between treatment groups $(\mathrm{P}>0.05)$. Less calvings were recorded with slight assistance in the restricted group compared to the control group $(\mathrm{P}<0.001)$. Cows with restricted silage access had a higher percentage of difficult calvings $(11 \%)$ compared to the control cows $(7 \%)(\mathrm{P}<0.001)$. Within the restricted group, there tended to be more dystocia during the day (12\%) compared to the night (8\%) $(\mathrm{P}<0.10)$. In the control group, there was no difference in the dystocia rate between the day $(7 \%)$ and the night $(8 \%)$ $(\mathrm{P}>0.05)$.

The percentage of stillborn calves was higher for cows in the restricted (7\%) compared to the control group $(5 \%)(\mathrm{P}<0.05)$. Within the restricted group, there was no difference in the stillbirth rate between the day (7\%) and the night (7\%) $(\mathrm{P}>0.05)$. Similarly, in the control group there was no difference in the stillbirth rate between the day $(5 \%)$ and the night $(6 \%)(\mathrm{P}>0.05)$.

Cows on restricted silage access that were fed as a group tended to have less calvings at night $(16 \%)$ than cows fed

Table 2: Effect of period of silage restriction and method of restriction on the percentage of cows calving by day and by night in the restricted feeding group $(\mathrm{n}=1,248)$

\begin{tabular}{|l|c|c|c|}
\hline & $\begin{array}{c}|c| \\
\text { Time of calving } \\
(06: 30 \text { to } \\
\text { 00:29h) }\end{array}$ & $\begin{array}{r}\text { Nighttime } \\
(00: 30 \text { to } \\
\text { 06:29h) }\end{array}$ & P-value \\
\hline $\begin{array}{l}\text { Period of silage } \\
\text { restriction (h) }\end{array}$ & & & \\
\hline 2 & 77.90 & 22.10 & \\
\hline 4 & 81.85 & 18.15 & \\
\hline 6 & 74.64 & 25.36 & \\
\hline 10 & 87.05 & 12.95 & 0.001 \\
\hline Method of silage & & & \\
\hline restriction & & & \\
\hline Group & 83.82 & 16.18 & \\
\hline Herd & 79.96 & 20.04 & 0.08 \\
\hline
\end{tabular}

as a herd $(20 \%)(\mathrm{P}<0.08)$ (Table 2$)$. The number of hours that cows were restricted from silage access influenced the percentage of calvings by night. The percentage of calvings at night was lower (13\%) when access to silage was restricted for 10 hours compared to 2, 4 or 6 h per day $(22,18,25 \%$, respectively) $(\mathrm{P}<0.001)$ (Figure 1). Calf sire breed did not affect the percentage of calvings by night: Holstein-Friesian (18\%); Aberdeen Angus (19\%); and Montbeliarde and Jersey (17\%). Cow parity had no effect on calving time with 19, 22 and $23 \%$ of first, second and older parity cows calving by night, respectively. Calf gender did not influence the percentage of calves born by night with $20 \%$ of male and of female calves born at night. The lower number of calvings per hour during the night compared to the day, irrespective of feeding system, is shown in Figure 2.

\section{Discussion}

Restricting access to grass-silage pre-calving reduced the number of cows calving at night by four percentage units, equivalent to a $24 \%$ reduction. The percentage of calvings at night $(18 \%)$ for cows on restricted access to silage found in the present study was similar to that $(17 \%)$ shown by Clarke et al., (1983). The percentage of calvings at night was lowest when access to silage was restricted for a $10 \mathrm{~h}$ period prior to feeding. This observation was similar to that reported by Gleeson et al. (2003). A long period on a prolonged restricted feeding time may influence energy intake and potentially influence calving ease. However, Gleeson et al., (2003) observed only a marginal reduction in DM (dry matter) intake with no difference in cow bodyweight, dystocia score or calf weight in a small scale study when cows had access to silage restricted for $10 \mathrm{~h}$ over a 12 -week period. Cows restricted as a group had less cows calving at night compared to cows restricted as a herd. This may be due to the difficulty in accurately estimating the amount of silage to feed to a herd in order to have a period of complete restriction to silage access. Hence, on occasion some silage may have remained during this restricted period. In this study, parity 


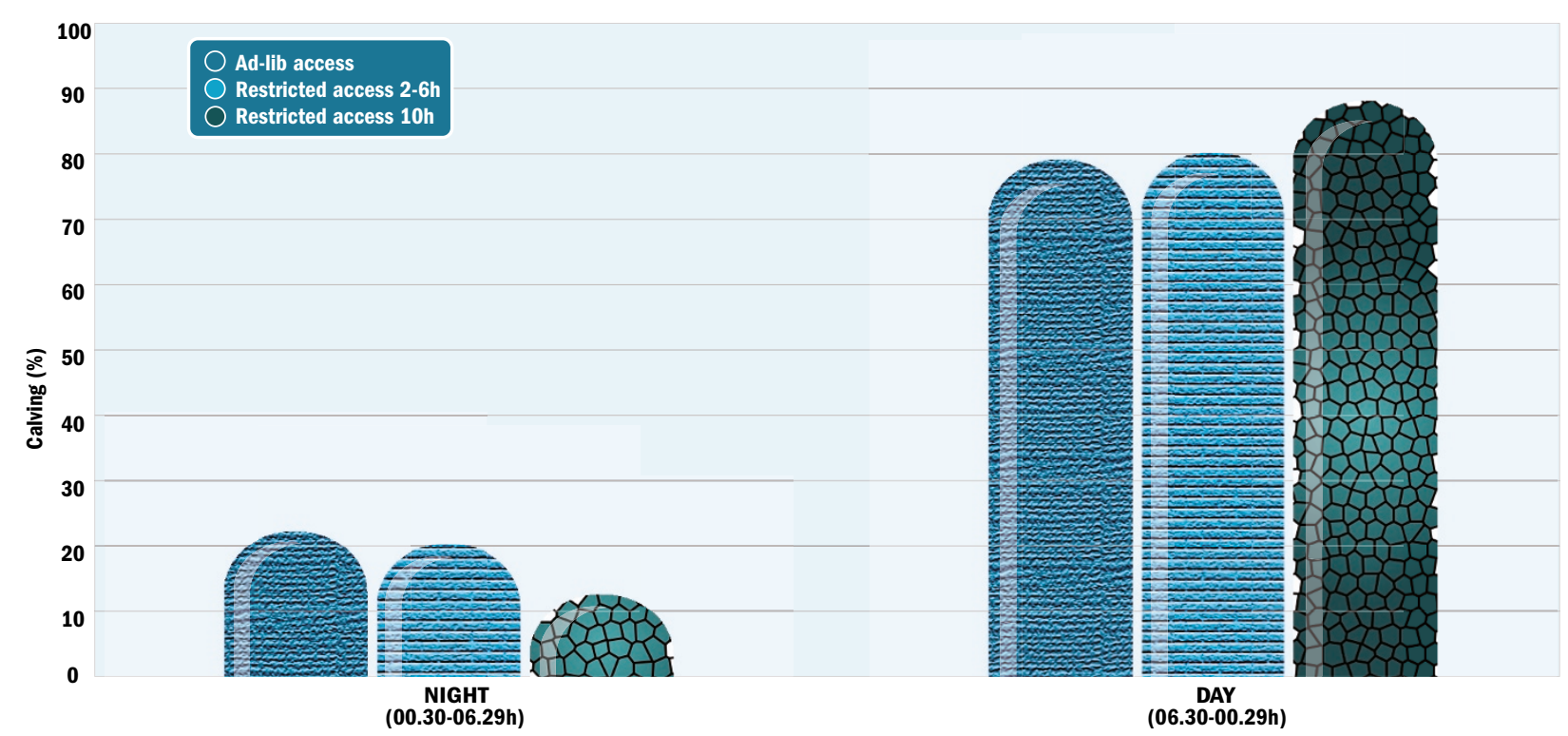

Figure 1: Distribution of calving (\%) during nighttime (00:30 to 06:29h) and daytime (06:30 to 00:29h) for cows with ad-lib access to silage and restricted access for $2-6 \mathrm{~h}$ or $10 \mathrm{~h}$ $(\mathrm{n}=2,441)$.

did not affect the distribution of calving throughout the 24h period. Makarechian (1984) showed that the frequency of nighttime calving was higher among first parity cows compared to older cows. However, a further study by Yarney et al., (1982) indicated that age of dam did not affect calving time.

The incidence of dystocia in this study was within the range (3-14\%) reported internationally for Holstein-Friesians (Mee, 2008). The higher incidence of dystocia in cows with restricted access to silage in the present study may be due to more calvings occurring during daylight hours when calving assistance was more likely to be available and premature assistance may have resulted in dystocia. This hypothesis is supported by both the higher incidence of dystocia in the restricted feeding group and the tendency for a higher incidence of dystocia amongst cows calving during the day in this group. Yarney et al., (1982) also found the highest incidence of calving assistance occurred from 11:00 to 15:00 (22\%) and the lowest incidence during the nighttime hours of 23:00 to $03: 00 \mathrm{~h}(12 \%)$ when farm labour was not available to assist at calvings. The higher incidence of stillbirth in the restricted feeding group may reflect the higher incidence of dystocia in that group. Dystocia is the primary risk factor for stillbirth in dairy cattle (Mee, 2004). However, the lack of difference in stillbirth rate between cows calving during the day or night in either group indicates dystocia was not the only cause of stillbirth in this study. No necropsy examinations were performed to ascertain the causes of stillbirth. Gleeson et al., (2003) found no difference in either stillbirth rate (4.0 vs $4.8 \%$ ) or calving assistance rate (14.4 vs $14.5 \%$ ) between cows on an ad-libitum diet of silage compared to restricted silage access even though there were differences in the number of calvings by day. This may be due to the same level of supervision for day and night calvings for that study. The stillbirth incidence in the present study was within the range (3.5-9.5\%) reported internationally for Holstein-Friesians and similar to that reported nationally by Mee et al., (2007).

In the present study, 22\% of cows calved between 01:00 and $06: 00 \mathrm{~h}$ and $30 \%$ calved between 13:00 and 19:00h when cows had ad-libitum access to silage. Macmillan et al., (1985) also reported an uneven distribution of calvings with $39 \%$ of cows calving in the same nighttime and $29 \%$ in the same day periods, for cows on a grass diet. However, Edwards (1979) recorded time of parturition for cows with ad-libitum access to silage and found that calving was evenly distributed throughout the $24 \mathrm{~h}$, with no bias towards day or night. Pennington and Albright (1985) also concluded that, irrespective of feeding time, $68 \%$ of beef cows could be expected to calve during daylight hours.

The results from this study indicate that restricting silage access prepartum may have a significant, but small, effect on calving time and this may in turn be associated with an increased risk of dystocia and stillbirth.

\section{Conclusion}

The hypothesis tested in this study, that restricting access to silage prepartum during the daytime and allowing access in the evening would reduce the number of nighttime calvings, was accepted, as the percentage of calvings was greater by day than by night in the treatment group. However, the effect of restricting silage access is confounded with time of feeding, as restricted cows were only offered fresh silage in the evening (commencing between 17:00 and 20:00h). The later the time in the evening that access to feed is allowed may be a factor in reducing the number of nighttime calvings. Feeding silage to cows in small groups, in the evening, after an extended period of restricted access appeared to give the optimum result in limiting the number of calvings by night. However, the hypothesis that a reduction in nighttime calvings would result in less dystocia was rejected, as a higher incidence of dystocia was observed 


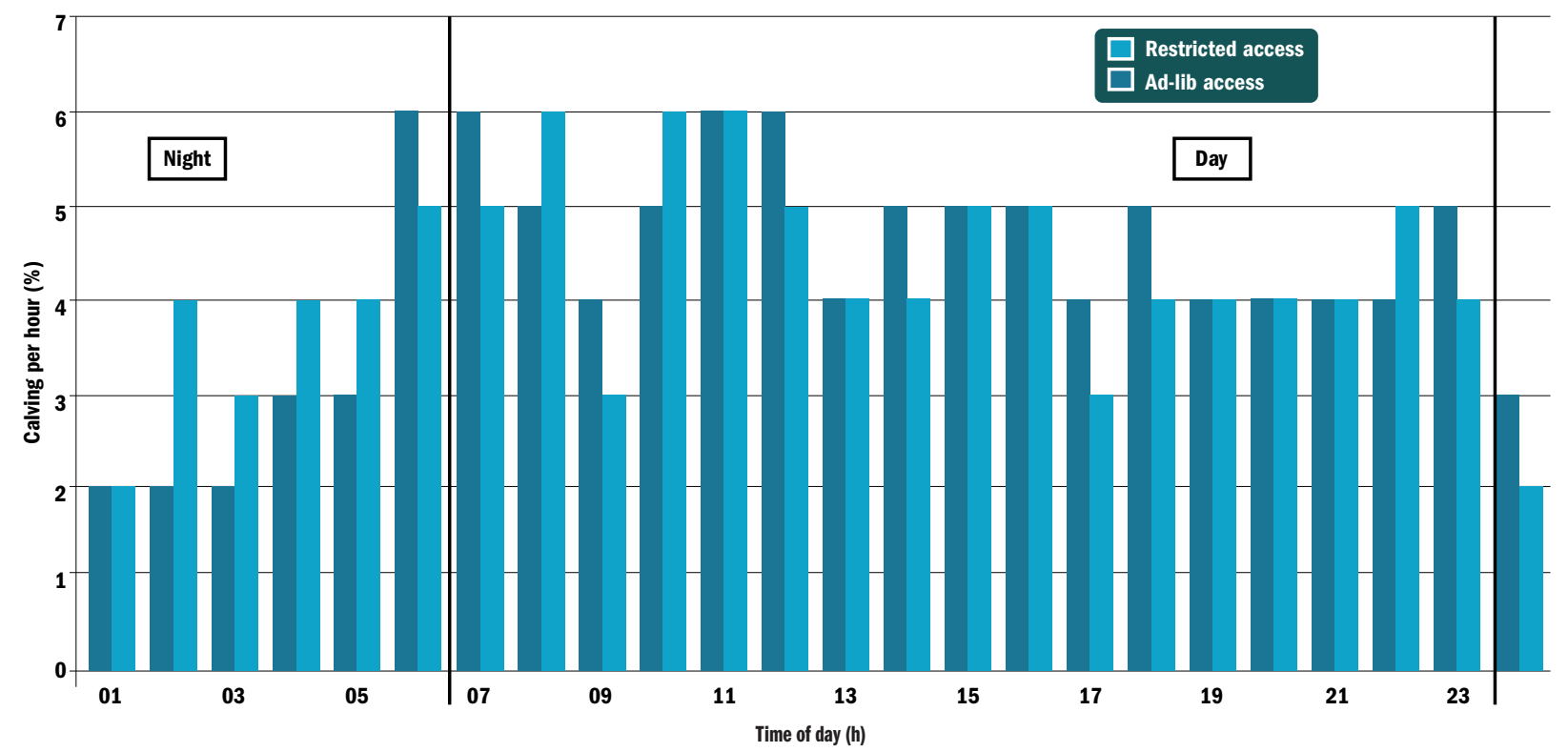

Figure 2: Distribution of calving per hour $(\%)$ for cows on restricted and $a d-l i b$ silage access $(n=2,441)$.

in cows with restricted access to silage; this may be due to more supervision during daylight hours and increased premature assistance and consequent stillbirth.

\section{Acknowledgements.}

The authors thank the dairy farmers who participated in this study for access to their herds and to their farm records. The financial support of the Irish Dairy Levy Research Fund is gratefully acknowledged.

\section{References}

Clarke, A.K., Spearow, A.C. and Owens, M.J. (1983). Relationship of feeding time to time of parturition for dry Holstein cows. Journal of Dairy Science. 66 (suppl. 1): 138.

Edwards, S.A. (1979). The timing of parturition in dairy cattle. Journal of Agricultural Science 93: 359-363.

Genstat 5 Release 3.2. (1995). Lawes Agricultural Trust (Rothamsted Experimental Station).

Gleeson, D.E., O'Brien, B., O'Donovan, K. and Mee, J.F. (2003). Effect of silage feeding regimen on time of calving and behaviour in HolsteinFriesian cows. International Journal of Applied Research in Veterinary Medicine 1: 311-317.

Lowman, B.G., Hankey, M.S., Scott, N.A. and Deas, D.W. (1981). Influence of time of feeding on time of parturition in beef cows. Veterinary Record 109: $557-559$.

Macmillan, K.L., Pearse, M.G., Copeman, P.J.A., MacDonald, K.A. and Kilgour, R. (1985). Effects of varying feeding time on diurnal calving patterns in dairy cows. Proceedings of the New Zealand Society of Animal Production 45: 35-37.

Makarechian, M. (1984). Factors influencing time of parturition in range beef cattle. Canadian Veterinary Journal 25: 450-452.

Mee, J.F. (2008). Prevalence and risk factors for dystocia in dairy cattle: a review. The Veterinary Journal (in press).

Mee, J.F. (2004). Managing the dairy cow at calving time. Veterinary Clinics of North America: Food Animal Practice 20: 521-546.

Mee, J.F., Cromie, A. and Berry, D. (2007). Risk factors for stillbirth in Irish dairy herds. Proceedings of the $58^{\text {th }}$ Annual Meeting of the European
Association for Animal Production p227.

O'Brien, B., O’Donovan, K., Gleeson, D., Ruane, D. and Kinsella, J. (2001). Profiling the working year on Irish dairy farms - identification of some work areas towards improvement in efficiency. Irish Grassland Association Journal 35: 128-140.

Pennington, J.A. and Albright, J.L. (1985). Effect of feeding time, behaviour and environmental factors on the time of calving in dairy cattle. Journal of Dairy Science 68: 2746-2750.

Stevenson, J.S. and Call, E.P. (1988). Reproductive disorders in the periparturient dairy cow. Journal of Dairy Science 71: 2572-2583.

Taverne, M.A.M., Breeveld-Dwarkasing, V.N.A., van Dissel-Emiliani, F.M.F., Bevers, M.M., de Jong, R. and van der Weijgen, G.C. (2002). Between prepartum luteolysis and onset of expulsion. Domestic Animal Endocrinology 23: 329-337.

Yarney, T.A., Rahnefeld, G.W., Knoefal, G., Boston, A.C., Mc Cannel, B., Sigurdson, M., Parker, R.J. and Palmer, W.M. (1979). Time of day of parturition in beef cows. Canadian Journal of Animal Science 59 (Abstr): 836. Yarney, T.A., Rahnefeld, G.W., Parker, R. J. and Palmer, W.M. (1982). Hourly distribution of time of parturition in beef cows. Canadian Journal of Animal Science 62: 597-605. 